\title{
Contaminated Land Guidance
}

The route to sustainable economic solutions 
Downloaded by [] on [25/04/23]. Copyright @ ICE Publishing, all rights reserved. 


\title{
Contaminated Land Guidance
}

\section{The route to sustainable economic solutions}

\author{
Third edition
}

Jo Strange, Nick Langdon and Alex Large

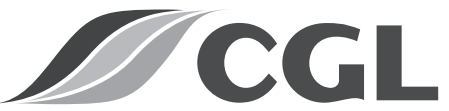

Providing Ground Solutions 
Published by ICE Publishing, One Great George Street, Westminster, London SW1P 3AA

Full details of ICE Publishing sales representatives and distributors can be found at: www.icebookshop.com/bookshop_contact.asp

\section{Other titles by ICE Publishing:}

UK Specification for Ground Investigation, Second edition. Institution of Civil Engineers. ISBN 978-0-7277-3506-5

Earthworks: A Guide, Second edition.

P. Nowak and P. Gilbert. ISBN 978-0-7277-4116-5

ICE Manual of Geotechnical Engineering.

J. B. Burland et al. ISBN 978-0-7277-3652-9

www.icebookshop.com

A catalogue record for this book is available from the British Library

ISBN 978-0-7277-6106-4

(C) Thomas Telford Limited 2017

ICE Publishing is a division of Thomas Telford Ltd, a wholly owned subsidiary of the Institution of Civil Engineers (ICE).

All rights, including translation, reserved. Except as permitted by the Copyright, Designs and Patents Act 1988, no part of this publication may be reproduced, stored in a retrieval system or transmitted in any form or by any means, electronic, mechanical, photocopying or otherwise, without the prior written permission of the Publisher, ICE Publishing, One Great George Street, Westminster, London SW1P 3AA.

This book is published on the understanding that the authors are solely responsible for the statements made and opinions expressed in it and that its publication does not necessarily imply that such statements and/or opinions are or reflect the views or opinions of the publishers. While every effort has been made to ensure that the statements made and the opinions expressed in this publication provide a safe and accurate guide, no liability or responsibility can be accepted in this respect by the authors or publisher.

While every reasonable effort has been undertaken by the authors and the publisher to acknowledge copyright on material reproduced, if there has been an oversight please contact the publisher and we will endeavour to correct this upon a reprint.

Commissioning Editor: Laura Balchin

Development Editor: Maria Inês Pinheiro

Production Editor: Rebecca Norris

Market Development Executive: Elizabeth Hobson

Typeset by Academic + Technical, Bristol

Index created by Laurence Errington

Printed and bound by Bell + Bain, Glasgow 


\section{Contents}

Preface

ICE Design and Practice Guides

About the authors

About the book

Acknowledgements

Glossary of abbreviations

01

\section{Introduction}

1.1. What is contaminated land?

1.2. Why is contaminated land a potential problem?

1.3. How big is the problem in the UK?

1.4. Risk-based framework

2.2. Risk management framework

2.3. Legislative framework

2.4. Roles and responsibilities

\section{Desk study}

04

\section{Ground investigation}

4.1. Introduction

4.2. Purpose

4.3. Investigation methodologies

4.4. Reporting

05

Risk assessment

5.2. Hazard identification and assessment 31

5.3. Risk estimation

5.4. Risk evaluation and communication

06

\section{Objective-based remediation design}

6.1. Risk mitigation 39

$\begin{array}{ll}\text { 6.2. Potential remediation objectives } & 39\end{array}$

6.3. RCL remediation objectives 39

6.4. Strategy-related objectives 41

6.5. Sustainable remediation 42

07

Options appraisal

7.1. Identification of constraints 45

7.2. Options identification $\quad 45$

7.3. Assessment of option feasibility 47

7.4. Quantitative assessment of option feasibility 48

7.5. Administrative measures 51

7.6. Conclusions 52

08

Design and implementation

8.1. Introduction 53

8.2. Planning and design 53

$\begin{array}{ll}\text { 8.3. Procurement } & 61\end{array}$

8.4. Implementation 63

Appendix A . . .

Useful organisations 
Appendix D.

Appendix E Summary of capabilities and limitations of commonly adopted remediation methods

Appendix F .

Waste management related to contaminated land

89

Index 


\section{Preface}

As pressure on land resources and from current statutory guidance increases, especially within an urban context, society and professional ethics demand sustainable solutions of engineers. Contaminated land, therefore, has become the subject of some importance to civil engineers looking to maximise developable space by reclaiming and recycling land.

Since the launch of the first edition in 1994, and the subsequent second edition in 2007, which set out the underlying risk assessment principles around which contaminated land issues can be assessed and mitigated, the available science has developed, and with it the detail of good practice. The 2012 Contaminated Land Statutory Guidance, along with government agency published risk assessment tools, have resulted in a framework of risk definitions and assessment methods which have revised the perception of acceptable risk. Further changes in European and UK Legislation, including health and safety regulations, have also impacted on how contamination is managed and can be economically remediated. In the context of this guide, the focus is on land contamination, which includes the water environment, but excludes air pollution, with sources of contamination being in solid, liquid or gaseous form.

It is important that professionals working in this subject area appreciate at the outset the necessity of involving experts in several different disciplines, since resolving contamination issues involves many technical and non-technical issues. In addition to civil and geotechnical engineering, expertise may be required in chemistry,

environmental science, geology, hydrogeology, industrial archaeology and project management, and may also be needed in other subjects such as chemical or process engineering, ecology, biology, valuation and other financial matters, and legislation. No one civil or geotechnical engineer can have the breadth of expertise that will allow them to address all aspects of a contaminated land project.

Certain aspects of land contamination are particularly specialised, such as radioactivity or some forms of military contamination such as explosives or chemical/biological weapons. These subjects are not addressed in the guide and expert advice must always be sought in this respect. 
Downloaded by [] on [25/04/23]. Copyright @ ICE Publishing, all rights reserved. 


\title{
ICE Design and Practice Guides
}

\author{
Practice Guides
} This document is the third edition of the ICE guide, first published in 1994. The purpose
of the guide, as with the previous editions, is to provide an introduction to the main principles and important aspects of contaminated land as it affects the construction industry and associated professionals. It offers guidance to the non-specialist as to appropriate procedures and sources for more detailed information. The aim is to summarise the key elements of current regulations and good practice as published in existing authoritative guidance documents prepared by key organisations such as central government, the Environment Agency, the Construction Industry Research and Information Association and the Building Research Establishment. It recognises that the whole area of contaminated land investigation and remediation has undergone significant changes since 1994 and the subsequent second edition in 2007 and will continue to do so for the foreseeable future.

The ICE continues to target as its principal audience of practising engineers who are not expert in or familiar with the subject matter. This group includes recently graduated engineers who are undergoing their professional training and more experienced engineers whose work experience has not previously led them into the subject area in any detail. In an environment where new regulation and its interpretation is the norm, those professionals who are more familiar with the subject may also find the guide of value as a handy overview or summary of the principal issues.

As before, the guide features aide-memoires on major aspects of the subject and refers to references and bibliographies, and guidance on authoritative, relevant and up-to-date published documents. Recognising the evolving nature of guidance and legislation, web references are provided where appropriate to keep the document as live and relevant as possible. 
Downloaded by [] on [25/04/23]. Copyright @ ICE Publishing, all rights reserved. 


\section{About the authors}

Jo Strange MEng CEng CEnv FICE FWES MIEnvSci SiLC

Jo is a Technical Director at Card Geotechnics Limited (CGL), and she is particularly skilled in the design, implementation and interpretation of geoenvironmental site investigations, remediation design and validation.

Her expertise includes quantitative risk assessment for soils, groundwater and ground gases, and the provision of specialist waste management advice with respect to contaminated soils. She is a registered Specialist in Land Condition (SiLC), a registered environmental auditor with IEMA, and a registered Qualified Person with Contaminated Land: Applications in Real Environments (CL:AIRE).

Nick Langdon MSc BEng DIC CEng CEnv FICE FGS

Company Chairman and Director of CGL, Nick has nearly 35 years' experience in geotechnical engineering. He has particular skills in the assessment and interpretation of site investigation data, slope analysis and stabilisation, and the design of foundations.

Nick has acted successfully as an Expert Witness on geotechnical issues in a number of cases in recent years.

Alex Large MSc BSc (Hons) CEnv MCIWEM MIEMA SiLC

Alex Large is an Associate Director in CGL's Exeter office, and is a registered SiLC. He has 15 years' professional experience as a geoenvironmental engineer, working on projects across Europe, Asia-Pacific and the USA.

Alex's professional experience includes managing and directing environmental site investigations, earthworks and multi-million-pound remediation contracts. Alex also has extensive experience in environmental management and auditing projects, along with the provision of sustainability due diligence services considering environment, health and safety, and social impacts and risks across a broad spectrum of sectors. 
Downloaded by [] on [25/04/23]. Copyright @ ICE Publishing, all rights reserved. 


\section{About the book}

This guide can only provide an overview of this very complex subject, and draws heavily on authoritative and comprehensive technical guidance documents prepared by other bodies.

The knowledge and practical experience of contaminated land has further matured and developed in the UK, with less reliance on international standards and more specific UK guidance having been published. Although legislation puts the onus on landowners and developers to address issues associated with contamination, the role of regulators has become key in maintaining basic standards, but is facing the constant challenge of budget cuts and skills shortages. There are several professional bodies looking at registration schemes to certify qualified experienced individuals such that regulators can have a degree of confidence in the quality of deliverables from such individuals, for example the existing Specialist in Land Condition scheme and the proposed National Quality Mark Scheme. These schemes are based on individuals being professionally committed to implementing adequate and appropriate risk management protocols.

This guide uses a systematic approach following sequential steps to a logical conclusion in accordance with current UK guidance. This approach takes the assessment from defining a basic conceptual site model based on anticipated hazards and risks to the next step of intrusive investigation. Beyond that, qualitative and quantitative risk assessment is used to support subsequent remediation design as appropriate to address the identified risks, taking account of the site use and client objectives. More so than ever, dealing with contaminated land requires a multidisciplinary approach. The use of appropriately experienced specialists is vital to achieving sustainable and technically sufficient investigation, assessment and remediation. Use of technical guidance documents such as this are no substitute for specialist expertise. 
Downloaded by [] on [25/04/23]. Copyright @ ICE Publishing, all rights reserved. 

Geotechnics Limited with acknowledgement of the original framework and sensible approach of the first edition set out by Mary Harris and Sue Herbert.

Grateful thanks is offered to Cognition Land and Water Ltd, DSM Demolition Ltd, GeoSonic Drilling Ltd, Goodman Ltd, Eastleigh Borough Council, Environmental Resources Management Ltd, Envirotreat Technologies Ltd, Lankelma Ltd and Vertase FLI Ltd, along with colleagues at Card Geotechnics Limited for their support with case studies and photographs. 
Downloaded by [] on [25/04/23]. Copyright @ ICE Publishing, all rights reserved. 


\section{Glossary of abbreviations}

\author{
AGS Association of Geotechnical and \\ Geoenvironmental Specialists \\ BGS British Geological Survey
}

BSI British Standards Institution

C4SL Category 4 Screening Level

CCME Le conseil canadien des ministres de l'environnement

CDM 2015 Construction (Design \& Management) Regulations 2015

CIEH Chartered Institute of Environmental Health

CIRIA Construction Industry Research and Information Association

CL:AIRE Contaminated Land: Applications in Real Environments

CLARINET Contaminated Land Rehabilitation Network for Environmental Technologies

CLEA

CLO

CLR

CP

CSM

Defra

EA

EHO

EPA

GAC

Contaminated land exposure assessment

Contaminated land officer

Contaminated Land Report

Cable percussive

Conceptual site model

Department for Environment, Food and Rural Affairs

Environment Agency

Environmental health officer

Environmental Protection Act 1990

Generic assessment criteria

GPR

GSV

HSE

JIWG

LLTC
Ground penetrating radar

Gas screening value

Health and Safety Executive

Joint Industry Working Group

(Asbestos in Soil and Construction \& Demolition Materials)

Low level of toxicological concern
A trade organisation established to improve the profile and quality of geotechnical and geoenvironmental engineering.

A world-leading geological survey that focuses on public-good science for government, and research to understand earth and environmental processes.

A services provider the principal activities of which are the production of standards and the supply of standards-related services.

Generic screening level defined by Defra in 2014 for evaluating risks to human health from contaminants in soil.

Produces the Canadian intervention values.

Regulations governing the safe planning and implementation of construction projects.

An independent professional organisation that represents the interests of the environmental health profession.

A research organisation dedicated to improving the performance of all those involved in construction and the environment.

An independent body promoting sustainable remediation of contaminated land and groundwater.

From 1998 to 2002, a body that developed technical recommendations and identified R\&D needs for the rehabilitation of contaminated sites in Europe.

A tool developed by the Environment Agency to facilitate the evaluation of risks to human health from contaminants in soil.

A local authority employee with a specific focus on contaminated land.

Series of guidance reports produced by the Environment Agency.

Drilling technique, also known as shell and auger.

The fundamental basis of any site assessment may be in tabular, graphical or text format.

Government department with environmental responsibilities.

A non-departmental UK public body with responsibilities relating to the protection and enhancement of the environment in England.

Local authority employee with a remit covering a range of environmental issues, often including contaminated land.

Integrated act covering emissions to the environment and waste management.

Conservative assessment criteria used to establish actual or potentially unacceptable risks from contaminants on a site. Typically, GACs are based on largely generic assumptions regarding the characteristics and behaviours of sources, pathways and receptors, within defined ranges of conditions.

Geophysical technique that uses radar pulses to map the subsurface.

A function of the gas flow and concentration, used to evaluate potential risks from ground gases.

UK body responsible for work-related health and safety.

Working group currently focused on coordinating asbestos management, occupational hygiene and brownfield management sectors, including the development of a harmonised approach.

Health criteria value based on low, as opposed to minimal, risk. 


\begin{tabular}{|c|c|}
\hline LNAPL & Light non-aqueous phase liquid \\
\hline LQM & Land Quality Management Ltd \\
\hline MCERTS & Monitoring Certification Scheme \\
\hline NICOLE & $\begin{array}{l}\text { Network for Industrially } \\
\text { Contaminated Sites in Europe }\end{array}$ \\
\hline NPPF & $\begin{array}{l}\text { National Planning Policy Framework } \\
2012\end{array}$ \\
\hline Part IIA & Part IIA of the EPA 1990 \\
\hline
\end{tabular}

PDL Previously developed land

Phase 1 Phase 1 Assessment

Phase 2 Phase 2 Assessment

PPE Personal protective equipment

QA/QC Quality assurance/quality control

QMLC NQMS for Land Affected by Contamination

QP Qualified person

RCL Relevant contaminant linkage

RPE Respiratory protective equipment

S4UL Suitable for use level

SGV Soil guideline value

SiLC Specialist in Land Condition

SoBRA Society of Brownfield Risk

Assessment

SQP Suitably qualified person

SuRF-UK UK Sustainable Remediation Forum

UKAS United Kingdom Accreditation Service

UXO Unexploded ordnance

WAC Waste acceptance criteria
A liquid that floats on water.

Environmental protection consultants.

An EA quality management scheme to provide the agency with confidence in the monitoring of emissions to the environment.

European contaminated land management forum, promoting cooperation between industry, academia and service providers on the development and application of sustainable technologies.

UK planning guidance document.

Primary regulatory mechanism used for the identification and remediation of a site in its current condition. Includes statutory definition of 'contaminated land'.

Also referred to as 'brownfield land', refers to land that has been used for a previous purpose or occupied by a structure.

A Phase 1 (also regularly referred to as a 'desk study', despite commonly including a site walkover) is the first tier of site assessment.

Phase 2 is commonly used to describe the intrusive investigation of a site (e.g. obtaining soil, groundwater, soil gas, etc. samples).

Protective clothing and equipment used by an individual.

Actions and procedures to maintain a desired standard.

Proposed scheme developed by the Land Forum to provide visible identification of documents that have been checked for quality by a suitably qualified and experienced person.

A specially trained, chartered individual registered with CL:AIRE, who is able to undertake the review of materials management plans and associated documents.

Pollutant linkages that have been identified through the risk assessment process to represent unacceptable risks.

Specific form of PPE used to protect the user.

Generic assessment criteria developed by LQM/CIEH used for evaluating risks to human health from soil contamination.

Generic assessment criteria developed by the EA used for evaluating risks to human health from soil contamination.

A senior geoenvironmental practitioner with a high level of understanding of land contamination issues, and significant professional experience.

A learned society established to support the growing number of professionals working in land contamination risk assessment.

An approved, registered individual who has the capacity to sign a declaration form for contaminated land reports under the QMLC.

An initiative set up to progress the UK understanding of sustainable remediation.

Quality assurance system for laboratories.

Explosive weapons that did not explode when they were detonated and may still pose a risk of detonation.

A minimum testing requirement that needs to be met for the disposal of hazardous and non-hazardous waste. The WAC limits must not be used to decide whether or not a waste is hazardous. 